\title{
Tecnologia e Educação: perspectivas e desafios para a ação docente
}

\section{Technology and education: perspectives and challenges for teaching activities}

Francisco Danilo Duarte Barbosa ${ }^{1 *}$, Erich de Freitas Mariano ${ }^{2}$, Jair Moisés de Sousa ${ }^{2}$

\begin{abstract}
RESUMO
O presente artigo discute a importância da utilização das Tecnologias da Informação e da Comunicação (TIC`s) na educação como recursos indissociáveis da prática docente e do processo de ensino e aprendizagem como um todo, haja vista que sua integração curricular, pedagógica e metodológica tornouse essencial para alunos e professores na sociedade contemporânea. Este artigo faz uma analise, por meio de questionário semiestruturado, das perspectivas e dos desafios enfrentados por professores de duas escolas públicas do sertão paraibano no uso dessas tecnologias em sala de aula como ferramentas mediadoras do processo de ensino e aprendizagem. Para tanto, utilizou-se como campo de pesquisa a escola Municipal de Ensino Fundamental Francisco Sales Gadelha de Oliveira, localizada no município de São Francisco e o Instituto Educacional de Ensino Fundamental e Médio Ronaldo Gonçalves Sarmento, situado no município de Lastro. As tecnologias são recursos indissociáveis da prática pedagógica dos docentes e sua utilização tem levado os educadores a transformar a sala de aula em espaços ativos de aprendizagem, criatividade, imaginação e construção do conhecimento. Porém, a falta de formação continuada e a indisponibilidade de recursos suficientes para o desenvolvimento de atividades didáticas desafiam os educadores e limitam o seu uso em sala de aula. Assim sendo, pensar o processo educativo como um todo, atualmente, pressupõe inovação na maneira de planejar e executar; pressupõe interação, dinamismo, compartilhamento de ideias e diferentes propostas de aprendizagem.
\end{abstract}

Palavra-Chave: Ensino e aprendizagem; Tecnologia educacional; Práticas pedagógicas.

\begin{abstract}
This article discusses the importance of using Information and Communication Technologies (ICT's) in education as inseparable resources of the teaching practice and the teaching-learning process in general, taking into consideration that it's curricular, pedagogical and methodological integration has become essential for students and teachers in the contemporary society. This study analyzes, through a semistructured questionnaire, the perspectives and challenges which teachers have to deal with in two public schools in the Sertão of Paraíba, when using these technologies at the classroom as tools for mediating the teaching-learning process. For such purpose, two public schools were used as research field, the Municipal Elementary School Francisco Sales Gadelha de Oliveira, located in the municipality of São Francisco, and
\end{abstract}

\footnotetext{
${ }^{1}$ Secretaria de Educação do Estado do Rio Grande do Norte/Secretaria Municipal de Educação de Lastro/PB *E-mail: fdanilo_barbosa@yahoo.com.br

${ }^{2}$ Universidade Federal de Campina Grande
} 
the Educational Institute for Elementary and High School Ronaldo Gonçalves Sarmento, located in the municipality of Lastro. The technologies are inseparable resources of the teaching practice and it's use has influenced teachers to transform classrooms into actives spaces for learning, creativity, imagination and knowledge development. However, the lack of continuous formation and the unavailability of sufficient resources for developing didactic activities challenge educators and limit it's use in classroom environment. Therefore, thinking the educational process in general, nowadays, estimates innovation in the planning and executing manners; estimates interaction, dynamism, sharing ideas and differents learning proposals.

Keywords: Teaching and learning; Educational Technology; Pedagogical Practices.

\section{INTRODUÇÃO}

Os avanços tecnológicos e de comunicação vem proporcionando um elevado dinamismo em todas as esferas da sociedade. Contudo, o ambiente escolar parece não acompanhar as mudanças de pensamento, de tecnologias e de metodologias de ensino. Nossos jovens estudam em escolas nas quais todos os ritmos, métodos e avaliações são uniformes e devem atingir todos os alunos igualmente. Este aspecto difere do que preza os anseios de uma educação voltada para as necessidades e habilidades próprias de cada sujeito, pois o ambiente escolar vive no mesmo ritmo da era industrial e não digital (XAVIER, 2015).

No contexto educacional brasileiro da atualidade, os avanços provocados pela sociedade contemporânea têm desafiado os educadores a oferecer uma formação para seus educandos compatível com as necessidades deste momento histórico. Neste cenário, haverá sempre uma necessidade real de buscar novas ideias de construção do conhecimento, do ensino e da aprendizagem. Isto implica repensar a função da escola e os papéis dos educadores e educandos.

A necessidade atual exige que as escolas sejam transformadas em ambientes de construção de conhecimento, não apenas de transferência dele. Neste processo de construção do saber, elementos relacionados ao tema aqui discutido, o ambiente escolar e principalmente, a individualidade do educando, devem ser levadas em consideração (SILVA, 2008). Esses elementos promovem uma contextualização do conhecimento e, para alguns, o saber se torna mais pertinente ao ser incluído em um cenário mais realista (MORIN, 2007). Trabalhar o conhecimento a partir de um contexto é perceber a "indissociabilidade do todo" e que abordagens multi e transdisciplinares na construção deste conhecimento são imprescindíveis. As relações estabelecidas entre a 
ação/experiência e suas consequências, ou seja, sua contextualização é o que proporciona uma real aprendizagem (PALAVAN et al., 2016).

Assim sendo, os impactos provocados pelos avanços tecnológicos nas instituições de ensino têm exigido mudanças constantes na maneira de educar. Mudanças que ultrapassam a tranquilidade de um sistema educativo social conservador, estático e tradicional, para um sistema educativo dinâmico e flexível.

O uso de tecnologias no ensino faz sua contribuição ao expandir os recursos disponíveis ao docente, tanto de forma material quando em forma de recursos metodológicos. Com seu emprego, os educandos podem trabalhar a autonomia, a criatividade e a interatividade através da investigação, experimentação e discussão de problemas reais associados ao conteúdo trabalhado (NASCIMENTO, 2016). Mas para que haja um real sucesso no emprego das tecnologias no ensino é preciso uma integração destas tecnologias ao ambiente escolar, não apenas sua aplicação direta em sala (SILVA, 2008). Se faz preciso uma "alfabetização informática, uma alfabetização científica e uma alfabetização em comunicação para que essa integração ocorra" (SILVA, 2008, p. 206).

Nessa perspectiva, a pesquisa fundamenta-se no seguinte problema: quais as perspectivas, desafios e importância do uso das TICs como ferramentas mediadoras do processo de ensino e aprendizagem? O estudo foi realizado mediante aplicação de questionário semiestruturado a 13 professores (6 de pedagogia, 2 de Educação Física, 1 de Ciências, 2 de História, 1 de Matemática e dois de Português) da Escola Municipal Francisco Sales Gadelha de Oliveira (EMFSGO) e 14 professores (6 de Pedagogia, 1 de História, 1 de Português, 1 de Ciências, 2 de Inglês, 1 de Educação Física, 1 de Matemática e 1 de Geografia)do Instituto Educacional de Ensino Fundamental e Médio Ronaldo Gonçalves Sarmento (IEEFMRGS), todos do Ensino Fundamental I, localizadas, respectivamente, nos municípios de São Francisco e Lastro, ambas no estado da Paraíba, Brasil. O questionário apresentou questões subjetivas e objetivas, seguindo o proposto por Matos (2002).

O estudo aqui descrito enquadra-se numa pesquisa explicativa (GONÇALVES, 2003), pois trata da descrição e entendimento dos fatores que levam aos docentes empregarem (ou não) ferramentas tecnológicas em suas práticas acadêmicas. Os dados coletados foram analisados com base no método de análise de conteúdos definido por Bardin (1977, p. 38) como: “(...) um conjunto de técnicas de análise das comunicações, que utiliza procedimentos sistemáticos e objetivos de descrição do conteúdo (...)”. 
As analises e discussões dos resultados foram subdivididos em dois momentos: o primeiro caracterizado pela natureza do uso das TICs, abordou o conceito, uso, presença, frequência e utilização dessas tecnologias em sala de aula. Foram analisadas ainda a formação e resistência dos professores quanto ao tema e objetivo em questão. No segundo momento foi discutido a organização e utilização das TICs mediante analise dos impactos, influencia e incentivos dessas tecnologias, bem como seu potencial para a aprendizagem.

Acreditamos que esta pesquisa contribuirá para reforçar a ideia de que a escola deve e pode incorporar as TIC`s como recursos indissociáveis de uma metodologia inovadora que proporciona o desenvolvimento de habilidades capazes de mudar e melhorar a forma de pensar dos educandos. Neste cenário, professor e educandos se deparam com novas formas de ensinar e aprender que podem sim, mudar suas vidas e a sociedade como um todo.

\section{EDUCAÇÃO E TECNOLOGIA NA SOCIEDADE CONTEMPORÂNEA}

As transformações surgidas, desde o surgimento do fogo, passando pela era agrícola e pela revolução industrial até a era da tecnologia e da informação, estão presentes em todos os campos e áreas da sociedade. Todas essas transformações tem se constituído um desafio para a educação.

Cada vez mais se exige um novo tipo de profissional, isto é, um indivíduo capaz de atuar em diversas áreas e funções. "Na educação, o comportamento flexível é tanto demandado dos professores quando difundido, como habilidade a ser adquirida, aos estudantes, futuros trabalhadores" (MOREIRA; KRAMER, 2007, p.05). Esse canário tem provocado a valorização de uma educação formadora de habilidades diversas.

É preciso reconhecer a multiplicidade de espaços na sociedade contemporânea que socializam, educam e culturalizam as pessoas, para então entender a educação como um processo social que se enquadra numa concepção de mundo vivida pela sociedade em diferentes tempos e espaços. A educação deve, neste sentido, adequar-se, constantemente, as mudanças da sociedade, sem negligenciar as vivências, os saberes básicos e os resultados da experiência humana.

Portanto, pensar o papel da educação nos dias atuais implica levar em consideração os avanços técnicos e científicos que a sociedade vem passando nas últimas décadas. Daí a necessidade de se explicitarem as mudanças desencadeadas no cenário 
educacional com o advento das tecnologias. Haja vista que com a inserção das tecnologias nas escolas, cria-se novos espaços de conhecimento e de aprendizagem.

Há, portanto, uma necessidade real de que os educadores se lancem à produção e/ou assimilação crítica de inovações de caráter pedagógico e didático, “[...] podendo, assim, aproveitar o estreito espaço de movimento existente no campo educacional, para gerar mudanças que não sejam simples expressões da modernidade" (BRITO, 2008, p.37).

É importante que o educador reflita constantemente sobre a forma como atua, sobre as técnicas que utiliza e de que modo a sua metodologia pode adaptar-se às características, às necessidades e aos interesses de seus alunos. Pois, "o trabalho docente é atividade que dá unidade ao binômio ensino-aprendizagem, pelo processo de transmissão-assimilação ativa de conhecimentos, realizando a tarefa de mediação na relação cognitiva entre o aluno e as matérias de estudo" (LIBÂNEO, 1994, p.88). Desse modo torna-se evidente as mudanças desencadeadas no cenário educacional com o advento das tecnologias.

Portanto, são múltiplas as possibilidades, benefícios e mudanças trazidas com a utilização das tecnologias na educação, contudo, para que tais mudanças sejam alcançadas e efetivadas no processo ensino e aprendizagem, é necessário que o professor participe efetivamente da implementação dessas mudanças começando por buscar uma formação sólida e adequada à utilização de tais recursos em sala de aula.

É neste cenário de mudanças constantes que a escola se consolida como uma instituição sumamente importante na formação do sujeito. É um espaço educativo de reflexão, mas, também, de práticas vivenciais capaz de ampliar o desenvolvimento intelectual, além de sistematizar a criação de valores humanos como a solidariedade, a justiça, a igualdade, a ética, o respeito, o amor, entre outros.

Assim sendo, o importante papel educativo que as escolas têm na sociedade contemporânea passa muito pela ação didática dos educadores que, num esforço consciente de sua prática pedagógica, possibilita a escola formar cidadãos críticos, reflexivos e autônomos, capazes de compreender a realidade em que vivem e de contribuir para a construção de uma sociedade mais justa e mais humana.

O paradigma educacional da modernidade, portanto, não nos permite mais termos um pensamento único, simplificado e fragmentado do conhecimento. Exige-se que visualizemo-nos uma realidade dinâmica e complexa, a qual a educação deve, 
prioritariamente, assumir um papel mais ativo dentro da sociedade. No entanto, a educação de hoje, por consequência "[...] a escola de hoje, em linhas gerais, tem uma prática muito distante da que é vivida pelo aprendiz nativo digital fora dela: ele é "analógica", basicamente tradicional, fundada nos pilares do instrucionismo [...]" (SILVA, 2012, p. 25).

Neste contexto, o advento da tecnologia na educação tem transformado radicalmente o que, como e onde o processo de ensino e aprendizagem acontece. A escola precisa não apenas conviver com as tecnologias, mas também integrá-las a sua proposta pedagógica a fim de preparar os indivíduos para uma nova sociedade. Isto implica que o conhecimento sobre tecnologias assumem papel importante na vida diária dos indivíduos.

O desafio, neste caso, é descobrir e criar usos criativos que inspirem os educadores a usá-la na prática pedagógica diária. Haja vista que as tecnologias são recursos importantíssimos para o processo de ensino e aprendizagem por serem ferramentas flexíveis, dinâmicas e atraentes para crianças, jovens e adultos. Sua integração ao currículo escolar potencializa as práticas pedagógicas voltadas ao desenvolvimento da autonomia do educando, além de impulsionar novas formas de aprender e ensinar, de aprender e interagir com o conhecimento e com o contexto local e global.

Para tanto, essa concepção de educação, de ensino e de aprendizagem precisa ser clara e objetiva, pois envolve conceitos e princípios, os quais sem a devida compreensão podem fragilizar qualquer iniciativa de melhoria da qualidade da aprendizagem dos educandos e de mudança significativa na prática pedagógica do professor em sala de aula. Tal processo "Não pode reduzir-se à intervenção domesticadora, tecnicamente fundada, que teria seu propósito no 'reflexo condicionado'. Comportamentos necessários, automatizados, perfeitamente previsíveis, seria o resultado" (DEMO, 2014, p.15).

A aprendizagem, neste caso, não precisa ser mais um processo solitário de aquisição e domínio de conhecimentos. Ela pode se dar de forma coletiva e integrada, articulando informações e pessoas que estão em diferentes locais e em diferentes idades, gênero, condições físicas, áreas e níveis de formação (KENSKI, 2003). Com essa concepção em mente, o educador deve se preparar para um papel mais ativo dentro da sociedade, pois as transformações e os avanços tecnológicos da sociedade contemporânea legitimam a morada da educação do futuro.

Desse modo, seja qual for a perspectiva que a educação contemporânea tomar, uma educação voltada para o futuro será sempre uma educação voltada para a 
transformação social do sujeito. Será sempre uma educação voltada para a formação integral do indivíduo, será sempre uma educação que levará o sujeito a viver e conviver em sociedade de forma consciente, ativa e participativa.

A transformação do sistema educacional passa, necessariamente, pela transformação da prática educativa. Não se trata, portanto, de buscar receitas, regularidades, mas sim de reinventar o existente e alterar o que mecanicamente está estabelecido. A educação é, e sempre será um elemento-chave na construção de uma sociedade baseada na informação, no conhecimento e no aprendizado.

\section{O USO DA TECNOLOGIA NA PRÁTICA PEDAGÓGICA DOS PROFISSIONAIS DOCENTES}

É somente a partir das ações democraticamente planejadas no ambiente escolar que podemos avaliar os avanços e retrocessos no processo de ensino e aprendizagem. Portanto, pensar na efetivação do ato educativo, ou nos processos pedagógicos empregados, é criar possibilidades de acesso ao conhecimento e transformação dele.

Nesses processos pedagógicos, as ferramentas tecnológicas muitas vezes são empregadas apenas como recursos audiovisuais, sem uma aplicação eficiente como métodos ativos. Vivemos na era da Revolução Eletrônica e a forma como os indivíduos se relacionam com as informações está sendo alterada a cada momento. A partir desse enquadramento histórico-cultural, o professor precisa estar devidamente integrado às diversas formas de interação entre tecnologias, conteúdos temáticos e alunos para se fazer mediador na construção do conhecimento.

Concordamos que os recursos tecnológicos podem contribuir de forma significativa com o processo de ensino e aprendizagem. Contudo, sua efetivação na prática pedagógica do professor só acontece quando o educador conhece as potencialidades e limitações que cada recurso pode oferecer. Desta forma, será capaz de utilizá-la como uma ferramenta que amplia as formas de ensinar e aprender. Para que esse processo ocorra, os docentes devem realizar uma constante atualização de conhecimentos científicos e tecnológicos (NASCIMENTO, 2016).

O esforço desprendido pelos professores nessas capacitações é significativo e a sua relevância no processo de ensino-aprendizagem tem sido amplamente reconhecida (ALMEIDA, 2001). Apesar do efeito positivo já registrado, o número de capacitações 
ainda é insuficiente, não apenas pela falta de pessoal qualificado para aplicar tais capacitações como pela sobrecarga de trabalho dos docentes e/ou pela falta de estrutura adequada nas escolas (SOUZA; BRANDÃO, 2017).

Ao analisar o uso da tecnologia nas salas de aulas das escolas pesquisadas, é essencial entender qual é o conceito de Tecnologia Educacional na visão dos professores. Tal conceito serve como um fator relevante para a construção e efetivação desse recurso na prática pedagógica na sala de aula, pois no contexto educacional, conceitos e definições teórico/metodológicas sobre tecnologia educacional estão a serviço da finalidade educativa do educador em um processo dinâmico e contextual (KENSKI, 2012). Ao perguntar aos professores sobre o conceito de Tecnologia Educacional, o Professor 08 afirmou compreendê-la como "[...] o conjunto de recursos e ferramentas digitais ou não que podem ser usadas como mediadores no processo de ensino e aprendizagem". Esse posicionamento está de acordo com o que defendemos em relação à tecnologia educacional: uma ferramenta que pode ser usada na prática diária do professor com o intuito de melhorar o processo de ensino.

É importante destacar que a definição de Tecnologia Educacional não pode ser considerada como um conceito fechado, haja vista serem amplas, portanto, difícil de ser definida de forma exata. Assim sendo, a tecnologia educacional é “[...] tudo aquilo que é usado em sala de aula com o propósito de oportunizar a aprendizagem de forma mais dinâmica e atrativa" (Professor 07); Além de ser "[...] uma ferramenta que auxilia no ensino-aprendizagem, visando melhorias na aplicação dos conteúdos e aquisição de conhecimentos" (Professor 18). Pelas definições apresentadas, entendemos que, de forma intrínseca, os docentes entrevistados entendem o conceito de Tecnologia Educacional, como proposto por Menezes e Santos (2001), sendo:

[...] a tecnologia educacional moderna engloba um forte componente de conhecimento científico - mas inclui também importante parcela de conhecimentos práticos, muitos dos quais só podem ser adquiridos através do próprio exercício da atividade a que se aplica. Essa tecnologia, portanto, não engloba apenas as máquinas que distribuem as mensagens, mas também a organização e as pessoas que a fazem funcionar (MENEZES; SANTOS, 2001, p.01).

Encaramos a tecnologia educacional como um conjunto de conhecimentos científicos, técnicos e práticos que contribuem para a reorganização e melhoria da qualidade dos processos de ensino. Tal conceito corrobora com a ideia de tecnologia 
defendida por Kenski (2012, p.24) quando ele diz ser “[...] um conjunto de conhecimentos e princípios científicos que se aplicam ao planejamento, à construção e à utilização de um equipamento em um determinado tipo de atividade [...]". Esta abordagem contribui para a ampliação do conceito de tecnologia educacional como um conhecimento globalizante construído historicamente pela evolução da sociedade.

De forma geral, os professores conhecem a importância do uso de tecnologias no ensino e até se sentem motivados a usá-las. Porém, sem os devidos investimentos em capacitação e atualização dos espaços educacionais a promoção da construção do conhecimento e motivação do pensar dos alunos fica prejudicada (FERREIRA, 2015).

Ao serem questionados sobre sua visão em relação ao uso das TICs na escola, $60,52 \%$ dos professores destacaram que utilizar as ferramentas tecnológicas é uma forma de aproximar os conteúdos ministrados com algo que desperte o interesse dos alunos, tornando a aula mais atrativa e dinâmica; 23,69\% afirmaram ser uma ótima opção de recursos pedagógicos, pois atrai o interesse dos alunos, uma vez que eles lidam diariamente com a tecnologia; já 15,79\% disseram que o uso das tecnologias é essencial para uma aprendizagem mais motivadora. Nenhum dos professores pesquisados afirmou que as TIC`s eram um recurso desnecessário no processo de ensino-aprendizagem.

O uso de tecnologias na formação do conhecimento potencializa o desenvolvimento pedagógico, justamente por poder trabalhar a autonomia, a investigação e a interatividade (CARVALHO; HIENKA, 2017). As tecnologias aplicadas ao ensino valorizam as práticas pedagógicas e os processos de compreensão de conceitos por utilizarem inúmeras representações, desde textos, imagens animadas/fixas, sons, construção de equipamentos e etc. (OLIVEIRA; TRINDAD, 2013).

Os dados apresentados destacam que o professor compreende ser importante o uso das tecnologias dentro do espaço escolar de sala de aula. Muitas vezes a falta desses recursos é que limitam a sua utilização. Por outro lado, algumas escolas dispõem dos recursos tecnológicos básicos para a atuação do educador e mesmo assim não são devidamente explorados pelos docentes. Em muitos casos eles se encontram acomodados com a metodologia tradicional, ou ainda por também estarem fora do ambiente de utilização de tais recursos.

Neste contexto, buscamos investigar: quais são os recursos tecnológicos que estão disponíveis nas escolas avaliadas. Quais desses recursos são efetivamente empregados e como é feito seu uso? Ao analisar as respostas dadas constatamos que as escolas dispõem 
dos seguintes equipamentos: Computadores, projetores, notebooks, TVs, DVDs, caixas de som amplificadas, laboratórios de informática, internet, aparelhos de som, microfones, calculadoras, impressoras e celulares. Todos estes equipamentos estão presentes nas duas escolas pesquisadas, o que nos leva a concluir que a utilização de tais recursos na prática pedagógica não está condicionada a falta de tais equipamentos.

Por outro lado, os recursos mais utilizados citados pelos professores são: o projetor, o computador, o notebook, a caixa de som, a TV, o DVD e o laboratório de informática. Estes equipamentos são utilizados pelos professores "[...] para apresentação de trabalhos dos alunos, como forma de mediar o conteúdo, exibição de vídeos, etc." (Professor 13); "para pesquisa, estudos e apresentação de conteúdos, imagens e atividades impressas” (Professor 18); “[...] para fazer a exposição dialogada do conteúdo através de slides" (Professor 14); Neste caso, os recursos tecnológicos são utilizados para fins pedagógicos de dinamização metodológica do professor, bem como para ampliação do acesso à informação e o conhecimento sobre o conteúdo abordado.

As ferramentas tecnológicas podem ser utilizadas no ensino de várias formas, desde mídias sociais até linguagens de programação para construções de animações ou softwares e construção de hardwares para desempenhar algum papel autônomo. Para tanto, se faz necessário uma reestruturação curricular e de estratégias pedagógicas (OLIVEIRA; TRINDAD, 2013). Essa reestruturação é apenas um dos problemas que encontramos ao tentar implementar o uso das tecnologias em ambientes educacionais. Cada região do país apresenta particularidades que exigem estratégias próprias para a introdução de suas práticas e as políticas públicas de inserção de espaços digitais ou tecnológicos nas escolas ainda são insipientes.

A interdisciplinaridade promovida através do uso de ferramentas tecnológicas no ensino já é um grande benefício na sua aplicação (CHASSOT, 2011). Contudo, a diversidade de recursos pedagógicos e a variedade de métodos que podem ser utilizados e que são proporcionados por estas ferramentas podem estimular os alunos a uma participação mais ativa, dinâmica e criativa, potencializando o aprendizado (RUPPENTHAL et al., 2011).

Alguns autores (e.g. MARTINHO; POMBO, 2009) há muito tempo já citam que a implementação de tecnologias no ensino cria ambientes mais motivadores, alunos mais atentos e empenhados no desenvolvimento de seus trabalhos e como consequência, um melhor rendimento nas avaliações. Por ser um dispositivo aberto, o computador estimula 
os estudantes a trabalhar seu conhecimento (PAPERT, 2007). Para Edgar Morin (2007) as TICs promovem melhoras na apreensão da realidade e favorece o desenvolvimento de todas as potencialidades do discente ao se constituírem em "pontes que ligam a sala de aula ao universo". Ao criar e interagir com um software ou hardware o aluno experimenta o "continuum experiencial" (DEWEY, 2015), no qual ele toma as decisões sobre a melhor forma de solucionar o problema em questão.

Neste contexto, entendemos que um dos grandes desafios a ser enfrentado por estes educadores que pouco utilizam as tecnologias em suas aulas é vencer o medo de inovar e de lançar-se ao desconhecido. Procurar conhecer as possibilidades de uso em sala de aula constitui-se o primeiro passo para usá-las como ferramenta pedagógica.

Alguns recursos tecnológicos ausentes nas escolas avaliadas, tais como internet de alta velocidade; "internet melhor, microfone individual e projetor de multimídia em cada sala" (Professor 04); "uma sala de vídeo organizada e com recursos tecnológicos disponíveis, pois economizaria tempo" (Professor 23); "mais notebooks, pois no momento, a escola não tem disponível para os professores que não possuem [...]" (Professor 07), são citados pelos docentes como essenciais na transformação de suas práticas pedagógicas.

Entre as tecnologias citadas pelos professores, a grande maioria já existe na escola, mas em quantidades insuficientes. Inevitavelmente essa realidade reflete no desenvolvimento das atividades docente, pois a quantidade de recursos é insuficiente para que as atividades planejadas aconteçam simultaneamente em todas as salas de aulas. Contudo, uma ação articulada e bem planejada entre os professores, o corpo pedagógico e a gestão escolar pode minimizar os impactos decorrentes das limitações desses recursos. Agindo assim, os docentes criam um ambiente favorável ao ensino, além de ampliar as possibilidades de sucesso do processo de ensino e aprendizagem.

Perguntamos aos professores de que maneira eles acreditavam que as instituições de ensino deviam se organizar para dinamizar, facilitar e possibilitar a utilização das tecnologias na sala de aula? A maioria dos docentes $(51,02 \%)$ destacou que as escolas devem investir na aquisição de materiais e equipamentos (projetor, computadores, internet). Tal posicionamento ocorre em decorrência das escolas não terem estes equipamentos em quantidade suficiente para todos os profissionais que atuam na docência. Já para 26,53\% dos professores, a escola deve investir na qualificação dos profissionais. 
Portanto, "é imprescindível orientar e educar os professores para se familiarizarem com os novos veículos da informação, para então estarem aptos a exercerem sua função na era tecnológica" (ALMEIDA, 2016, p.13). A qualificação profissional pode levar os educadores a rever seus conceitos, sua metodologia e a forma de aprendizagem dos educandos, além de aumentar o seu potencial criativo e inovador.

Ao serem perguntados sobre que cursos de formação continuada gostariam de receber, 53,57\% citaram cursos de Utilização pedagógica de softwares educacionais. É fundamental que a formação dos professores para o uso pedagógico das TICs esteja vinculada à realidade da escola e a prática diária do professor, "caso contrário, conseguiremos dar um verniz de modernidade, sem mexer no essencial" (MORAN et al., 2012, p. 63). Outros 8,16\% destacaram a importância do desenvolvimento de políticas de incentivo à formação continuada através de cursos de educação à distância. A educação à distância, aliás, tem se tornado uma ferramenta essencial na vida dos profissionais da educação, pois a maioria deles tem buscado essa modalidade de ensino devido à flexibilidade de horários e a maior facilidade de adequar sua jornada de trabalho com a qualificação profissional.

Nas escolas, no entanto, ainda é possível encontrar quem seja resistente ao uso das tecnologias, tal constatação foi evidenciada quando 14,28\% dos professores afirmaram que a escola só precisa investir no incentivo ao uso do livro didático como recurso prioritário para o processo de ensino e aprendizagem. Tal posicionamento está em desacordo com o que acreditamos ser o movimento da educação na sociedade atual. É importante deixar claro que defendemos o uso do livro didático em sala de aula de forma articulada com outros recursos tecnológicos como, por exemplo, o computador, a internet, o projetor, as vídeos-aulas, etc.

Ao articular os diversos recursos disponíveis na escola, o professor será capaz de "transmitir" o conhecimento de forma diferenciada. Mas o uso adequado de tecnologias no ensino desenvolve capacidades estratégicas e de comunicação (CARVALHO; GUIMARÃES, 2016), habilidades essenciais para o mundo das ciências. E o processo de interação entre os alunos e entre os alunos e professores causado pelo dinamismo no uso das tecnologias em salas de aulas possibilitam um melhor entendimento de aspectos relacionados a vida dos estudantes, e permitem com isso uma nova forma de construir o processo de ensino-aprendizagem (RAMOS; COPPOLA, 2009). 


\section{O EDUCADOR COMO ORGANIZADOR DO CONHECIMENTO PARA A UTILIZAÇÃO DA TECNOLOGIA EM SALA DE AULA}

A ação docente é a base para a construção de uma aprendizagem significativa. Com essa concepção surge a necessidade dos educadores elaborarem, desenvolverem e avaliarem novas práticas pedagógicas de sala de aula. É essencial que o educador estabeleça a construção de uma nova relação com o saber, ultrapassando, assim, os limites da linearidade dos materiais instrucionais tradicionais.

Perguntamos aos professores quais os impactos positivos e negativos que obtiveram com a utilização da tecnologia em sala de aula? Em resposta ao questionamento citado, obtivemos que o ponto positivo é a "atenção maior dos alunos, redução de exposição de um conteúdo e variadas formas/possibilidades de ilustração” (Professor 03); "uma melhor aceitação da aula" (Professor 09); além de "quebrar aquela rotina de aula monótona e desperta a curiosidade dos alunos [...]" (Professor 21). Em razão disso, tais recursos devem ser explorados sistematicamente para que a aprendizagem ocorra em articulação com a realidade dos estudantes.

Devemos ter em mente que a aprendizagem é um processo de mudança comportamental moldado pela interligação de processos neurológicos, relacionais, emocionais e ambientais (VAZZI, 2017). Dessa forma, na concepção do aprendizado as inúmeras possibilidades de interação são elementos fundamentais.

Alguns elementos podem participar e direcionar a interatividade entre o sujeito e o objeto de aprendizagem. Dentro desses elementos mediadores podemos incluir o professor, o livro ou mesmo as ferramentas tecnológicas. Contudo, a construção do conhecimento depende do engajamento do aluno e de sua transformação no principal elemento ativo do processo (VAZZI, 2017).

A principal forma de trabalho dos métodos de aprendizagem ativa versa em conduzir os alunos a problematizar aspectos de sua própria realidade e relacioná-los com os temas estudados (BERBEL, 2011). Nos métodos ativos, o principal impulsionador do aprendizado é a superação dos desafios por meio da resolução de problemas e a construção de novos saberes a partir de experiências prévias, da interação com colegas e da construção de significados (DEWEY, 1959; FREIRE, 1996). Aprender a partir da tradução e reconstrução das experiências é aprender usando o "como para saber" e esses são elementos essenciais no processo de transformação da educação (MORIN, 2015). 
Sendo a educação um processo no qual o objetivo final se encontra no seu próprio desenvolver, as metodologias ativas apresentam-se como eficientes ferramentas educacionais.

Em face ao apresentado, percebemos que a utilização das tecnologias em sala de aula leva a construção de sentidos e significado dos conteúdos abordados, superando a monotonia e a imparcialidade das aulas expositivas. Além disso, criam novos cenários que facilitam a aprendizagem e tornam a escola atrativa, atual e a enquadra na nova era da informação e da comunicação.

Contudo, a utilização de tais recursos pelos professores também apresenta pontos negativos como, por exemplo: "não saber utilizá-la com eficiência" (Professor 05); e dificuldade com o "manuseio dos equipamentos" (Professor 03). Além da falta de recursos como internet, computadores, projetor, e espaço físico adequado. Tal posicionamento vai de encontro novamente ao já citado neste texto: os pontos negativos da utilização de tais recursos estão sempre atrelados ao quantitativo existente na escola.

O fato é que a tecnologia é imparcial no tocante a sua capacidade de produzir características positivas ou negativas. Cabe então ao professor saber como utilizá-la de forma eficiente e edificante, pois só assim os resultados da influência tecnológica serão consequentemente benéficos para o processo de ensino e aprendizagem. Os resultados positivos e negativos, portanto, dependem muito do uso que se faz dela, de como e com que finalidade ela está sendo usada. O professor precisa estar consciente de que a adoção das tecnologias na sala de aula tem reflexos na sua prática docente e nos processos de aprendizagem dos educandos.

É preciso ressaltar que a tecnologia não é o ponto principal do processo de ensino e aprendizagem, mas um recurso que proporciona a articulação entre educador, educando e os saberes escolares. Assim é essencial que se supere a concepção de ensino centrado na exposição didática do conteúdo. Neste contexto, perguntamos aos professores em que a tecnologia (computadores, internet, TV) se difere de outros meios de transmissão de informação e como podemos potencializar seu uso no processo de ensino e aprendizagem? Isto porque sua inserção na educação exige muito mais do que o conhecimento técnico, exige, além de tudo, compromisso, responsabilidade e vontade de mudar.

Uma maneira de potencializar o uso é incentivar os alunos a pesquisarem em sites voltados aos conteúdos estudados em sala de aula" (Professor 02), pois, "são mais ágeis 
na transmissão de informações e tem uma abrangência maior" (Professor 18). Com esse posicionamento percebemos o quanto a tecnologia pode aproximar a sala de aula com aquilo que o aluno está acostumado no seu dia a dia.

São informações em tempo real que chegam a todo o momento através da internet, dos jornais televisivos, dentre outros. Cabendo ao professor orientar o aluno a ser capaz de filtrar as informações verdadeiras, a buscar sites confiáveis e se posicionar crítico e consciente. É nesta perspectiva que a tecnologia "se difere principalmente na velocidade com que a informação é propagada [...]" (Professor 03). Ao incentivar a pesquisa, professores e alunos passam a compartilhar a mesma ideia, pois abertura, flexibilidade, comunicação e interação são fatores que mantêm relação intrínseca com o uso pedagógico das tecnologias em sala de aula.

O conteúdo on-line é atraente, pois pode ser encontrado em diferentes formatos, e atendem a quase todas as necessidades e estilos de aprendizagem das pessoas, independente da precisão do conteúdo. Consequentemente, os estudantes procuraram na internet para encontrar mais informações de forma rápida. Um dos métodos preferidos de acessar o conteúdo é assistindo vídeos on-line em plataformas de compartilhamento (SILVA et al., 2019).

A forma como as informações online são utilizadas pelos alunos e seu impacto no processo de ensino-aprendizagem ainda precisa ser melhor avaliada. Contudo, o estudo online como complemento ao estudo presencial já é uma realidade e as instituições de ensino precisam estar alinhadas com essa possibilidade.

Portanto, "a dinamicidade proposta pelas tecnologias é indiscutivelmente mais atraente quando comparada ao uso do livro didático" (Professor 09). Partindo deste pressuposto, fica mais evidente ainda a necessidade de mudança, principalmente no que diz respeito ao uso da tecnologia em sala de aula. Assim, as tecnologias

[...] sejam elas novas (como o computador e a Internet) ou velhas (como o giz e a lousa) condicionam os princípios, a organização e as práticas educativas e impõem profundas mudanças na maneira de organizar os conteúdos a serem ensinados, as formas como serão trabalhadas e acessadas as fontes de informação, e os modos, individuais e coletivos, como irão ocorrer as aprendizagens (SILVA, 2010, p.76).

Cabe às escolas coordenar todo esse processo de transformação da prática pedagógica oferecendo condições para que o professor possa atuar na construção da formação cidadã dos alunos. Condição necessária para que os educandos possam exercer 
sua cidadania com autonomia em uma sociedade democrática. Neste cenário, os educadores têm a grande responsabilidade de atualizar-se e orientar seus alunos para o uso consistente de tudo que é oferecido através de recursos tecnológicos como computador, TV, internet, redes sociais, entre outros.

Assim sendo, perguntamos aos professores se através do uso de tecnologias como, por exemplo, a internet, ele aprofunda o conhecimento sobre os conteúdos curriculares e de que maneira ela influência a sua metodologia em sala de aula? Haja vista que essas ferramentas tem se tornado importante aliadas do professor ao permitir tratar o conteúdo em sala de aula de forma mais vivo, dinâmico e atual.

A internet "[...] influencia na facilidade de uma melhor abordagem com formas mais variadas de apresentação e dinamização" (Professor 03). Ela também "ajuda nas pesquisas, [...] na aprendizagem" (Professor 11). Tudo isso corrobora com a ideia de que o papel do professor é decisivo na integração curricular das tecnologias com o processo de ensino e aprendizagem.

É necessário que as pesquisas e o aprofundamento teórico e prático demonstrado pelos professores nas respostas anteriores sejam também usados em sala de aula com seus alunos. Neste contexto, perguntamos aos professores se eles incentivam seus alunos a fazerem pesquisas na internet, assistirem vídeos-aula, responder questionários on-line? E de que forma elas ajudam o aluno na sua aprendizagem? Isto porque o uso da internet propicia a criação de ambientes motivadores, interativos, colaborativos e cooperativos (MORAN et al., 2012, p.99).

Baseado na ideia de interação e conectividades proposto para ser desenvolvido em sala de aula, os professores destacaram incentivar seus alunos a utilizarem a tecnologia para pesquisa e aprofundamento do conteúdo estudado porque "[...] ao pesquisar, o aluno vai desenvolvendo a leitura e [...] a curiosidade por determinados temas [...]" (Professor 21); Destacaram ainda que incentiva “[...] sempre, inclusive, indico canais do youtube, sites especializados em utilizar os materiais didáticos, etc. Os alunos dessa forma, acabam criando um maior interesse pelo aprendizado" (Professor 27); além disso "[...] ajudam a entender como os conteúdos pode se apresentarem com diferentes complexidades e que nem tudo é verdadeiro" (Professor 03). Portanto, mais que aprender a decorar o conteúdo, o aluno precisa aprender a acessá-lo, a pensar e a refletir.

Com essa visão, enfatiza-se a necessidade de instigar o aluno a ter o prazer de descobrir, de investigar, de construir e reconstruir conhecimento. Pois, é "inútil tentar 
conhecer tudo. Isso supõe uma cultura geral, o que não prejudica o domínio de certos assuntos especializados. Aprender a conhecer é mais que aprender a aprender" (GADOTTI, 2000, p.251).

Cabe ao docente criar e estabelecer novos formatos metodológicos para que ambos (professor e alunos) possam trabalhar em parceria para a aquisição do conhecimento, pois a construção do conhecimento, nesta perspectiva, está intimamente ligada à forma como o educador explora tais recursos.

Computador e internet na sala de aula nas mãos de professores treinados formam um importante instrumento de ensino. Ter acesso à internet não é mais uma questão de aumentar a capacidade de raciocínio. Passou a ser vital. É como saber ler e escrever nos anos 50 (SCWARTZ, 1999, p.32).

Para que a sala de aula se torne um espaço de aprendizagens significativas é necessário que tais recursos estejam presentes e atuantes no processo de ensino. Com este pensamento, perguntamos aos professores se ao utilizar as tecnologias da informação e da comunicação, ele explora novas possibilidades de aprendizagens com seus alunos? Como? Haja vista que tais tecnologias têm o potencial de funcionar como facilitadoras de acesso à informação e ao conhecimento.

Os professores pesquisados destacaram que tais recursos são utilizados para explorar novas possibilidades de aprendizagens, como: "incentivando a pesquisa, a leitura. Utilizando-se de filmes, músicas e imagens" (Professor 04); "Sim, orientando-os para fontes seguras compatíveis com o que está sendo estudado" (Professor 21); "Sim, procurando levar novidades para sala de aula, seja uma atividade prática no computador ou até mesmo no celular, que é uma ferramenta muito usada pelos alunos" (Professor 21);

As possiblidades metodológicas de uso das tecnologias apresentadas pelos professores retratam algumas características em comum como: a relevância da interação, a flexibilização espaço/temporal, a variedade das fontes de acesso e a necessidade do aprofundamento na compreensão do conteúdo, além da pesquisa e da exploração dos recursos. Tais experiências pedagógicas aumentam o campo de ação pedagógica do professor, já que "ensinar e aprender exige, hoje, muito mais flexibilidade espaçotemporal, pessoal e de grupo, menos conteúdos fixos e processo mais abertos de pesquisa e de comunicação" (MORAN et al., 2012, p.29).

Cada professor estabelece uma relação particular com o uso das tecnologias na sua prática pedagógica influenciada pelos múltiplos fatores que configuram o ato 
educativo. O cenário tecnológico requer novos hábitos, uma nova gestão do conhecimento, novas formas de conceber, armazenar e transmitir o saber (BRITO; PURIFICAÇÃO, 2008). Para tanto, é preciso que o aluno seja instigado a buscar o conhecimento, a ter prazer em conhecer, em pensar e em elaborar e reelaborar sua maneira de aprender a aprender. Se não for encarado desta maneira, os recursos utilizados em sala de aula podem se tornar "[...] reprodutores dos velhos vícios e erros dos sistemas [...]" (BRITO; PURIFICAÇÃO, 2008, p.24).

O uso das tecnologias da informação e da comunicação apresenta perspectivas inovadoras e desafios constantes para os educadores, portanto, sua inserção na educação exige integração e apropriação em um processo crítico-reflexivo. Esse tem sido o grande desafio pedagógico para os educadores, não sendo diferente com os que participaram desta pesquisa.

Portanto, as mudanças desencadeadas pela sociedade do conhecimento têm desafiado os educadores no sentido de oferecer uma formação/aprendizagem compatível com as necessidades desse momento histórico. O eixo da ação docente, atualmente, precisa ultrapassar a ideia de ensinar através da exposição didática mecanicamente para focar no aprender, principalmente, no aprender a aprender.

Este objetivo exige o domínio dos recursos tecnológicos de modo a criar as condições necessárias para a produção do conhecimento, pois a produção do saber demanda ações que levem professor e aluno a buscarem caminhos coletivos na busca por uma formação mais humana e compatível com as exigências da sociedade contemporânea.

\section{CONSIDERAÇÕES FINAIS}

A discussão aqui retratada vem evidenciar a importância da tecnologia na educação. A inserção de ferramentas tecnológicas no ensino vem provocando transformações significativas no ato educativo na sala de aula devido o giz, o quadronegro e os livros didáticos não serem mais os únicos recursos disponíveis e pela ativação dos alunos no processo de aprendizagem. É importante entender que a qualidade e o modo de ensino mudam em razão das mudanças pela qual a sociedade vem passando desde suas origens até os dias atuais. 
Reforçamos a ideia de que a escola deve e pode incorporar as TIC's como recursos indissociáveis de uma metodologia inovadora, que proporciona o desenvolvimento de habilidades capaz de mudar e melhorar o cotidiano do aluno. Neste cenário, professor e aluno se deparam com novas formas de ensinar e aprender que podem, sim, mudar suas vidas e a sociedade como um todo.

Dentre os recursos que a instituição pode e deve disponibilizar para os educadores, damos destaque aos recursos tecnológicos, pois ao serem utilizados na sala de aula, conduz tanto docentes quanto discentes a compartilharem ideias e aprenderem juntos, somando e dividindo conhecimentos. O uso adequado de tecnologias no ensino desenvolve capacidades estratégicas e de comunicação (CARVALHO; GUIMARÃES, 2016), habilidades essenciais para o mundo das ciências. O uso de imagens de alta definição, microscópios ou equipamentos de coleta de dados ambientais tornam o mais acessível a compreensão de fenômenos próprios da biologia (SUDÉRIO, 2014).

Os educadores que investem em novas estratégias e recursos pedagógicos, dentro dos padrões existentes na escola "mais tarde, animam-se a realizar algumas mudanças pontuais e, só depois de alguns anos são capazes de propor inovações, mudanças mais profundas em relação ao que vinham fazendo até então" (MORAN et al., 2012, p. 90).

O processo de interação entre os alunos e entre os alunos e professores causado pelo dinamismo no uso das tecnologias em salas de aulas possibilitam um melhor entendimento de aspectos relacionados a vida dos estudantes, e permitem com isso uma nova forma de construir o processo de ensino-aprendizagem (RAMOS; COPPOLA, 2009).

A realidade da hiperinformação deve ser objeto de reflexão permanente, com vista a entender quais as perspectivas e os desafios enfrentados pelos educadores no uso das tecnologias da informação e da comunicação em sala de aula. Tendo em vista que as inovações produzidas pelas tecnologias contribuem de modo decisivo para transformar a escola em um lugar de exploração de culturas, de aprendizagens, de produção do conhecimento, de realização de projeto, de investigação e de debate (KENSKI, 2012).

Considerando este cenário, a pesquisa, ora apresentada, destaca a necessidade de reflexão/ação/reflexão sobre o uso das tecnologias da informação e da comunicação na educação, pois a diversidade de situações pedagógicas criadas por estes recursos permite ao professor a reelaboração e a reconstrução permanente do seu processo de ensino e aprendizagem. Ao longo do estudo tornou-se perceptível a mudança na forma de pensar 
dos professores em relação ao uso das tecnologias em sala de aula, entretanto ainda encontramos aqueles que são resistentes, inseguros e que não acreditam nos benefícios que as TIC's proporcionam ao ato educativo. Apesar de apontarmos inúmeros caminhos e relatos que comprovam benefícios e vantagens, ainda resistem ao seu uso, e quando o utilizam, agem de forma mecânica. Somente com capacitação, formação continuada e políticas públicas de incentivo ao uso das TIC`s, estes professores poderão mudar seus paradigmas educacionais, suas concepções, verem os benefícios e sentirem-se seguros para utilizarem em sala de aula.

Adaptar-se aos seus avanços, ao número reduzido de equipamentos nas escolas e apropriar-se, metodologicamente, das potencialidades de cada recurso de maneira que promovam a aprendizagem dos alunos são os maiores desafios enfrentados pelos educadores das escolas pesquisadas. Para a superação desses desafios é necessário que o educador esteja aberto às mudanças e a inovação. Só assim será capaz de incorporar, vivenciar e transformar a realidade educacional em que se encontra.

Concluímos afirmando que a efetivação e a apropriação das tecnologias na educação não é um caminho fácil, contudo, hoje, é irreversível. Com interesse, dedicação e compromisso é possível aprender, planejar e executar uma ação educativa prazerosa, lúdica, atrativa e interativa em sala de aula. É agindo assim que o professor deixa de lado as amarras culturais, metodologias formativas e tradicionais, deixando de ser o detentor do saber cientificamente construído e passando a ser um mediador, um facilitador, um colaborador, um agente propulsor de aprendizagens significativas.

\section{REFERÊNCIAS}

ALMEIDA, A. M. Educação em Ciências e Trabalho Experimental: Emergência de uma nova concepção. En A. Veríssimo, M. A. Pedroza e R. Ribeiro (Orgs.), Ensino Experimental das Ciências: (Re) pensar o ensino das ciências (pp. 55-74). Lisboa: Ministério da Educação, 2001.

ALMEIDA, I. C. Escola e tecnologia educacional: desafios contemporâneos. 2016. 45 f. Trabalho de Conclusão de Curso (Graduação Pedagogia). Universidade Estadual de Londrina, Londrina, 2016. Recuperado de: http://www.uel.br/ceca/pedagogia/pages/arquivos/2016\%20Isabel\%20Cristina\%20de\%2 0Almeida.pdf.

BARDIN, L. Análise de conteúdo. Tradução Luiz Antero Reto e Augusto Pinheiro. Lisboa: Edições 70, 1977. 
BERBEL, N. A. N. As metodologias ativas e a promoção da autonomia de estudantes. Semina: Ciências Sociais e Humanas, 3 (1), 25-40, 2011. Recuperado de: http://www.uel.br/revistas/uel/index.php/seminasoc/article/view/10326.

BRITO, G. S.; PURIFICAÇÃO, I. Educação e novas tecnologias um re-pensar. Curitiba: Ibpex, 2008.

CARVALHO, L. J.; GUIMARAES, C. R. P. Tecnologia: um recurso facilitador do ensino de Ciências e Biologia. En VIII Encontro internacional de formação de professores, Aracaju, SE. Anais do VIII Encontro internacional de formação de professores, Aracaju, SE, UNIT, v.9(1), 2016. Recuperado de: https://eventos.set.edu.br/index.php/enfope/article/view/2301.

CARVALHO, L. S.; HIENKA, V. Formação de professores em consonância com as novas tecnologias. Revista Eletrônica Científica Inovação e Tecnologia, 8(21), 2017. Recuperado de/; http://books.scielo.org/id/fp86k/pdf/sousa-9788578793265-01.pdf.

CHASSOT, A. Alfabetização científica: questões e desafios para a educação. $5^{\mathrm{a}} \mathrm{Ed}$. Ijuí: UNIJUÍ, 2011.

DEMO, P. Desafios Modernos da Educação. 19ª Ed. - Petrópolis: Vozes, 2014.

DEWEY, J. Democracia e educação. São Paulo: Companhia Editora Nacional, 1959.

DEWEY, J. Experience and Education. Nova Iorque: Free Press, 2015.

FERREIRA, P. J. C. Arduino Science Kits: plataforma open-hardware para práticas laboratoriais no ensino das ciências experimentais. 2015. 138 f. Dissertação (Mestrado em Sistemas e Tecnologias de Informação para organizações). Instituto Politécnico de Viseu, Viseu, 2015. Recuperado de: http://repositorio.ipv.pt/handle/10400.19/3103.

FREIRE, P. Pedagogia do oprimido. São Paulo: Paz e Terra, 1996.

GADOTTI, M. Perspectivas atuais da educação. Porto Alegre: Artes Médicas Editora, 2000

GONÇALVES, E. P. Conversas sobre iniciação à pesquisa cientifica. $3^{\mathrm{a}} \mathrm{Ed}$. Campinas: Alínea, 2003.

KENSKI, V. M. Educação e tecnologia: O novo ritmo da informação. $8^{a}$ Ed. Campinas: Papirus, 2012.

LIBÂNEO, J. C. Didática. São Paulo: Cortez, 1994.

MARTINHO, T.; POMBO, L. Potencialidades das TIC no ensino das Ciências Naturais - um estudo de caso. Revista Eletrónica de Enseñanza de las Ciencias, 8(2), 527-538, 2009. Recuperado de: http://reec.uvigo.es/volumenes/volumen8/ART8_Vol8_N2.pdf.

MATOS, K. S. L. Pesquisa educacional: o prazer de conhecer. $2^{\text {a }}$ Ed. Fortaleza: Edições Demócrito Rocha, 2002.

MENEZES, E. T.; SANTOS, T. H. Verbete tecnologia educacional. Dicionário Interativo da Educação Brasileira - Educabrasil. São Paulo: Midiamix, 2001. Recuperado de: http://www.educabrasil.com.br/tecnologia-educacional/.

MORAN, J. M.; MASETTO, M. T; BEHRENS, M. A.Novas tecnologias e mediação pedagógica. 19a Ed. Campinas: Papirus, 2012. 
MOREIRA, A. F. B.; KRAMER, S.Contemporaneidade, educação e tecnologia. Educação \& Sociedade, 28(100), 1037-1057, 2007. Recuperado de: http://www.redalyc.org/pdf/873/87313704019.pdf.

MORIN, E. Educação e complexidade: Os sete saberes e outros ensaios. $4^{\text {a }}$ Ed. São Paulo: Cortez, 2007.

Ensinar a viver. Porto Alegre: Editora Sulina, 2015.

NASCIMENTO, J. F. T. F. A Utilização da plataforma Arduino na realização de trabalho experimental em aulas de Ciências Naturais. 2016. 198 f. Dissertação (Mestrado em Didática das Ciências da Natureza e da Matemática). Instituto Politécnico do Porto, Porto. Recuperado de: https://recipp.ipp.pt/handle/10400.22/11360.

OLIVEIRA M. C. A.; TRINDAD, G. S. Análise de artigos apresentados nos Encontros de Nacionais de ensino de Biologia (ENEBIO) sobre o tema aulas práticas

experimentais. In IX Encontro Nacional de Pesquisa em Educação em Ciências, Águas de Lindóia, SP, 2013. Anais do IX Encontro Nacional de Pesquisa em Educação em Ciências, Águas de Lindóia, ABRAPEC, 1-7. Recuperado de: http://www.nutes.ufrj.br/abrapec/ixenpec/atas/resumos/R0057-1.pdf.

PALAVAN, O.; CICEK, V.; ATABAY, M. Perspectives of Elementary School Teachers on Outdoor Education. Universal Journal of Educational Research, 4 (8), 1885-1893, 2016. Recuperado de: http://www.hrpub.org/download/20160730/UJER1919507067.pdf.

PAPERT, S. A. A máquina das crianças: Repensando a escola na era da informática. Porto Alegre: Artmed, 2007.

RAMOS, O. M.; COPPOLA, N. C. Uso do computador e da internet como ferramentas pedagógicas. 2009. Disponível em: $<$ http://www.diaadiaeducacao.pr.gov.br/portals/pde/arquivos/2551.

RUPPENTHAL, R.; SANTOS, T. L.; PRATI, T. V. A. Utilização de mídias e TICs nas aulas de Biologia: como explorá-las. Cadernos de Aplicação, 24(2), 377-390, 2011. Recuperado de: https://seer.ufrgs.br/CadernosdoAplicacao/article/view/18163.

SCHWARTZ, C. Janelas Para o Futuro. Veja Vida Digital, São Paulo, ano 32, p. 32, 1999.

SILVA, B. D. A tecnologia é uma estratégia. Tecnologias de Educação: ensinando e aprendendo com a TIC. Brasília: Ministério de Educação à Distância, 2008.

SILVA, L. O. A formação do professor da educação básica para o uso da tecnologia: a complexidade da prática. In Junia de Carvalho Fidelis BRAGA (Org.). Integrando tecnologias no ensino de Inglês nos anos finais do Ensino Fundamental. São Paulo: Edições SM, 22-39, 2012.

SILVA, M. A. D.; PEREIRA, A. C. e WALMSLEY, A. D. Who is providing dental education content via YouTube? British Dental Journal, 226, 437-440, 2019.

Recuperado de: https://www.nature.com/articles/s41415-019-0046-8.

SILVA, M. Sala de aula interativa: a educação presencial e a distância em sintonia com a era digital e com a cidadania. En XXIV Congresso Brasileiro da Comunicação,

Campo Grande, MS. Anais do XXIV Congresso Brasileiro da Comunicação, Campo Grande, CBC, 2010. Recuperado de: 
http://www.portcom.intercom.org.br/pdfs/8072553987228989203832352378943560483 4.pdf.

SOUZA, L. W. e BRANDÃO, H. C. Aulas práticas e sua importância no ensino de ciências e biologia. Revista Eletrônica Científica Inovação e Tecnologia, 8(21), 1-20, 2017. Recuperado de: https://periodicos.utfpr.edu.br/recit/article/view/e-4963/pdf.

SUDÉRIO, F. B.; NASCIMENTO, M. B.; SANTOS, C. P. e CARDOSO, N. S. Tecnologias na educação: análise do uso e concepções no ensino de biologia e na formação docente. Revista SBEnbio. 7(1), 2014.

VAZZI, M. R. G. (2017). O Arduíno e a Aprendizagem de Física: Um kit robótico para abordar conceitos e princípios do Movimento Uniforme.2017. 107 f. Dissertação (Programa de Pós Graduação em Educação Escolar). Faculdade de Ciências e Letras, Universidade Estadual Paulista "Júlio de Mesquita Filho", Araraquara. Recuperado de: http://bdtd.ibict.br/vufind/Record/UNSP_6f2da3b2aa76328e87eabfb8b11660eb.

XAVIER, L. G. Para além da didática: desafios da escola e do professor do século XXI. Exedra: Revista Científica, 1, 26-36, 2015. Recuperado de:

https://dialnet.unirioja.es/servlet/articulo?codigo $=6496624$.

Recebido em: 01/06/2021

Aprovado em: 20/06/2021

Publicado em: 30/06/2021 